University of Wollongong

Research Online

Faculty of Engineering and Information

Faculty of Engineering and Information

Sciences - Papers: Part A

Sciences

2016

An experimental and numerical investigation on micro rolling for ultra-thin strip

Haibo Xie

University of Wollongong, xie@uow.edu.au

Kenichi Manabe

Tokyo Metropolitan University

Tsuyoshi Furushima

tsuyoshi@uow.edu.au

Kazuo Tada

Tokyo Metropolitan University

Zhengyi Jiang

University of Wollongong, jiang@uow.edu.au

Follow this and additional works at: https://ro.uow.edu.au/eispapers

Part of the Engineering Commons, and the Science and Technology Studies Commons

Research Online is the open access institutional repository for the University of Wollongong. For further information contact the UOW Library: research-pubs@uow.edu.au 


\title{
An experimental and numerical investigation on micro rolling for ultra-thin strip
}

\author{
Abstract \\ The demand for miniaturized parts and miniaturized semi-finished products is increasing nowadays, \\ because microforming processes can improve production rate and minimize material waste due to less \\ forming passes. However, traditional macro metal forming processes and modelling cannot be simply \\ scaled down to produce miniaturized micro parts. In this study, a 2-Hi micro rolling mill has been \\ successfully built. Experimental and numerical investigations on the micro rolling process for ultra-thin \\ SUS 304 stainless steel strip have been conducted. The experimental results show that the micro rolling \\ deformation of ultra-thin strip is influenced by size effect which results from the specimen size difference \\ and this size effect is embodied in the flow stress and the friction coefficient. Analytical and finite \\ element (FE) models in describing size effect related phenomena, such as flow stress, friction, rolling \\ force and deformation behaviour, are proposed. The material surface constraint and the material \\ deformation mode are critical in determination of material flow stress curve. The analysis of surface \\ roughness evolution with rolling conditions has also been performed. The identified analysis on \\ deformation mechanics provides a basis for further exploration of the material behaviour in plastic \\ deformation of micro scale and the development of micro scale products via micro rolling.

\section{Keywords} \\ ultra, thin, rolling, micro, investigation, numerical, experimental, strip \\ Disciplines \\ Engineering | Science and Technology Studies

\section{Publication Details} \\ Xie, H. B., Manabe, K., Furushima, T., Tada, K. \& Jiang, Z. Y. (2016). An experimental and numerical \\ investigation on micro rolling for ultra-thin strip. International Journal of Material Forming, 9 (3), 405-412.
}




\title{
An experimental and numerical investigation on micro rolling for ultra-thin strip
}

\author{
H.B. Xie ${ }^{\mathrm{a}, b^{*}}$, K. Manabe ${ }^{\mathrm{a}}$, T. Furushima ${ }^{\mathrm{a}}$ K. Tada ${ }^{\mathrm{a}}$ and Z.Y. Jiang ${ }^{\mathrm{b}}$ \\ a'Department of Mechanical Engineering, Tokyo Metropolitan University, Tokyo 192-0397, Japan \\ ${ }^{\mathrm{b}}$ School of Mechanical, Materials and Mechatronic Engineering, University of Wollongong, \\ Wollongong, NSW 2522, Australia
}

\begin{abstract}
The demand for miniaturized parts and miniaturized semi-finished products is increasing nowadays, because microforming processes can improve production rate and minimize material waste due to less forming passes. However, traditional macro metal forming processes and modelling cannot be simply scaled down to produce miniaturized micro parts.

In this study, a 2-Hi micro rolling mill has been successfully built. Experimental and numerical investigations on the micro rolling process for ultra-thin SUS 304 stainless steel strip have been conducted. The experimental results show that the micro rolling deformation of ultra-thin strip is influenced by size effect which results from the specimen size difference and this size effect is embodied in the flow stress and the friction coefficient. Analytical and finite element (FE) models in describing size effect related phenomena, such as flow stress, friction, rolling force and deformation behaviour, are proposed. The material surface constraint and the material deformation mode are critical in determination of material flow stress curve. The analysis of surface roughness evolution with rolling conditions has also been performed. The identified analysis on deformation mechanics provides a basis for further exploration of the material behaviour in plastic deformation of micro scale and the development of micro scale products via micro rolling.
\end{abstract}

Keywords Micro rolling, rolling characterization, surface roughness, size effect, ultra-thin strip.

*Corresponding author: Tel.: +81-426773015; fax: +81-426772701; E-mail address: hx899@uowmail.edu.au

\section{INTRODUCTION}

Micro forming technology, a promising process for improving production rate and minimizing material waste, is now becoming more and more important in industries of miniaturized products. However the deformed material cannot be considered as a homogeneous continuum like the material in the macro scale metal forming because its behaviour in micro forming is characterized by only a few grains in the deformation area [1-3]. Therefore material deformation behaviour, such as friction characterizations and surface interactions, in micro scale should be well identified. A number of researchers have conducted related research work in micro forming. The influences of specimen thickness and grain size on material behavior have been investigated in the processing of thin metal sheets [2-4]. The analytical model combined with the share of surface grains can be developed to theoretically describe the decrease in flow stress with the findings from the material data obtained in the tensile test [5].The evolution of friction behaviour from micro size to macro size is studied and a new uniform friction model is proposed based on the assumption of open-closed lubricant pockets [6]. The FE-based model has also been experimentally validated in terms of loads and enabled more accurate and flexible friction modelling [7]. Simulation has been applied in surface roughness modelling and size effect $[8,9]$. Using the multi-region model, the coining process with micro feature is simulated to investigate the size effect [9]. Tribological analysis is of considerable importance in cold rolling process. The friction modelling and surface roughness deformation have been reported in refs [10-17]. Le and Sutcliffe apply a tribological model for mixed lubrication in rolling of thin strip and foil and this model indicates that the friction coefficient on the asperity contact is related to a theoretical oil film thickness and secondary-scale roll surface roughness [10,11]. The surface is found to crush roughly with a large increase in contact area with bulk strain [15]. Friction coefficient clearly increases with an increase of the relative roughness and the ratio of tool roughness to specimen roughness [16].The combined effects of friction, macroscopic deformation, roll roughness and lubricant viscosity influence the loads during cold rolling. For foil rolling, refs [18-22] have reported some related research. The deformation of foil rolling, where there are two stage reductions in the rolling deformation zone, is different and complex from the traditional macro metal forming. Fleck and Johnson [20,21] assume that the roll profile includes a central flattened region for the deformed rolls, and the pressure is taken to be near Hertzian and the deviation of the roll profile from flat is incorporated by using a modified Winkler mattress model. However there are few researches focused on such hard material as stainless steel foil rolling in 2-Hi micro rolling mill. 
In this study, experimental and numerical investigations have been conducted on ultra-thin strips of SUS 304 stainless steel by micro rolling to study and to evaluate the influence of the specimen size. The size effects on the flow stress curves and friction coefficient due to the variations of specimen size are clearly demonstrated. The analytical and FE models for describing the size effect related phenomena, such as the change of flow stress, friction and deformation behaviour are proposed. The experimental results can be used to validate the numerical model. A combination of the friction law and stress flow model, respectively can be brought together to be finally applied to micro rolling process.

\section{EXPERIMENT AND SIMULATION}

\section{Experimental equipment and tested materials}

The experiment consists of tensile test, friction test and micro rolling process. The tensile test and friction test provide the Stress-Strain curve and friction coefficient respectively, for the rolling process simulation. The research on rolling deformation behaviour for SUS 304 stainless steel is carried out on a micro rolling mill in dry friction without lubricating oil. The reduction in foil thickness for each pass varies according to the rolling schedule. The rolled foil is collected, measured and compared after each pass.

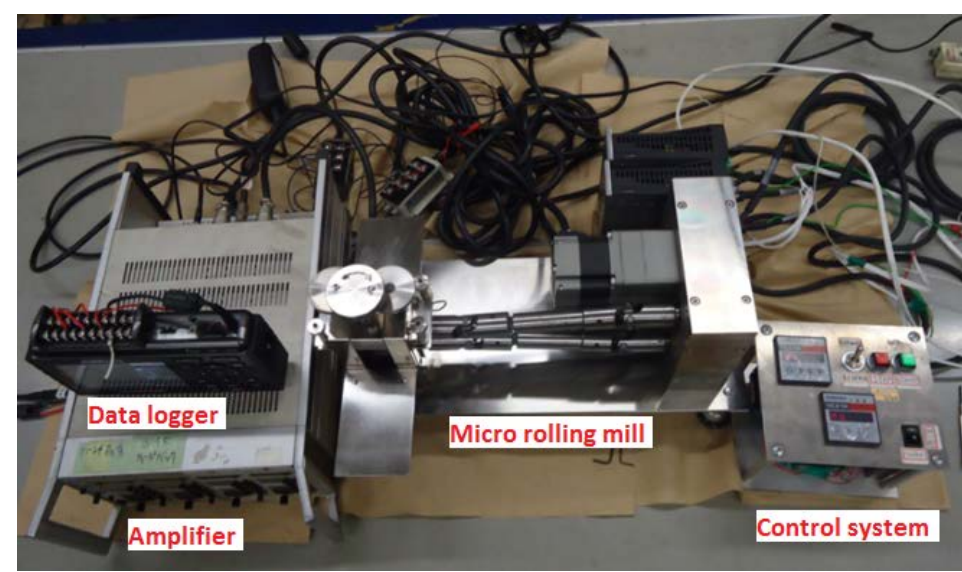

Fig. 1 New desktop micro rolling mill

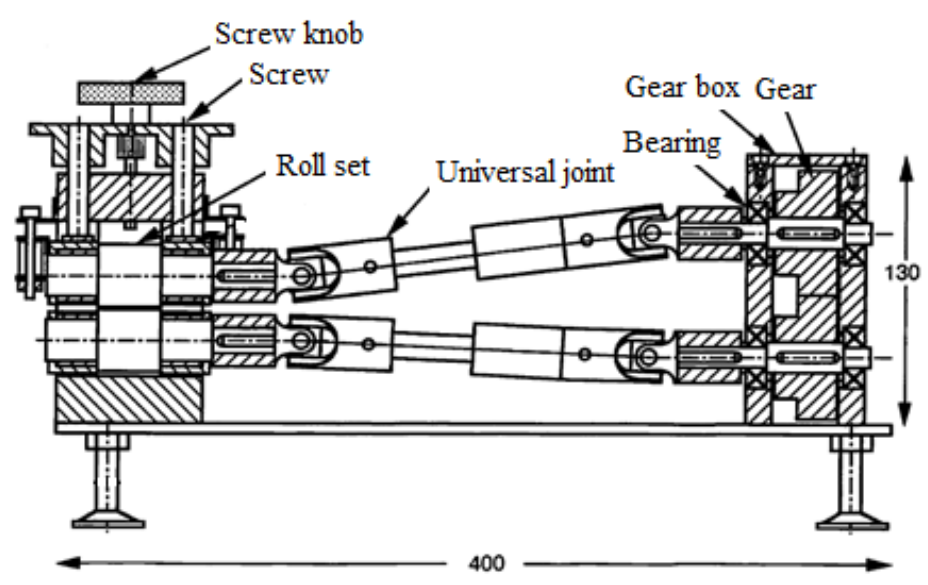

Fig. 2 Schematic rolling mill, unit: mm

Fig. 1 shows the new desktop micro rolling mill system, which includes micro rolling mill, control system, and date collection devices: pressure amplifier and data logger. Multi-pass and reversing rolling is available in this rolling mill. This new micro rolling mill is scaled down and easy to move and install on the desk and it is suitable for hard material rolling with low roll elastic deformation due to high rolling mill stiffness. The rolls are driven by motor via the gear system. The schematic rolling mill set is shown in Fig. 2 where the size of micro rolling mill is indicated. The length and height of rolling mill set are only $400 \mathrm{~mm}$ and $130 \mathrm{~mm}$, respectively. 
Various thickness reductions can be obtained through adjusting roll gap by the screw knob in Fig. 2.

Table 1Rolling mill description

\begin{tabular}{|c|c|c|c|c|}
\hline Rolling mill & Work roll (*diametel & $\Phi 27 \mathrm{~mm})$ & Roll barrel length & Rolling speed \\
\hline & Material & Young's Modulus (GPa) & & \\
\hline 2-Hi & SKD 11 & 210 & $29.5 \mathrm{~mm}$ & $\begin{array}{c}0-30 \mathrm{rpm} \\
(0-42.4 \mathrm{~mm} / \mathrm{s})\end{array}$ \\
\hline reverse mill & Cemented carbide & 580 & & \\
\hline
\end{tabular}

The rolling mill is described in Table 1. It is noted that two materials of tool steel (SKD 11) and sintered hard alloy (cemented carbide) with high Young's modulus of $580 \mathrm{GPa}$ are used as work roll materials in this rolling mill. The annealed austenitic SUS 304 stainless steel is prepared as experimental material and the 2-Hi desktop-scale reverse mill is used for multi-pass rolling. The initial material thicknesses are $100 \mu \mathrm{m}$ and $50 \mu \mathrm{m}$ with width of $15 \mathrm{~mm}$, respectively. The chemical composition of SUS304 stainless steel is listed in Table 2.

Table 2 Chemical composition of SUS 304 stainless steel (wt \%).

\begin{tabular}{ccccccc}
\hline $\mathrm{C}$ & $\mathrm{Si}$ & $\mathrm{Mn}$ & $\mathrm{P}$ & $\mathrm{S}$ & $\mathrm{Ni}$ & $\mathrm{Cr}$ \\
\hline 0.05 & 0.44 & 1.18 & 0.033 & 0.001 & 8.22 & 18.23 \\
\hline
\end{tabular}

\section{Finite element modelling}

The rolling simulation is carried out with the explicit dynamic finite element code, LS-DYNA. The SOLID164 element type has been used (a three dimensional 8 NODE solid element) for the simulation. Refined meshing is employed around the surface roughness of the rolled strip to improve the simulation accuracy and further surface roughness calculation [8].

Table 3 Properties of the roll and the rolled strip in simulation

\begin{tabular}{ccc}
\hline Items & Roll & Steel strip \\
\hline Material model & Elastic & Elasto-plastic \\
Density, $\mathrm{kg} / \mathrm{m}^{3}$ & $7.85 \times 10^{3}$ & $7.85 \times 10^{3}$ \\
Young's Modulus, $\mathrm{MPa}$ & $2.1 \times 10^{5}(\mathrm{SKD} 11) / 5.8 \times 10^{5}$ (Cemented carbide) & $2.1 \times 10^{5}$ \\
Poisson's ratio & 0.3 & 0.3 \\
Dimension & Roll neck in diameter: $9 \mathrm{~mm}$ & Thickness: 100 and $50 \mu \mathrm{m}$ \\
& Roll barrel in diameter: $27 \mathrm{~mm}$ & Width: $15 \mathrm{~mm}$ \\
\hline
\end{tabular}

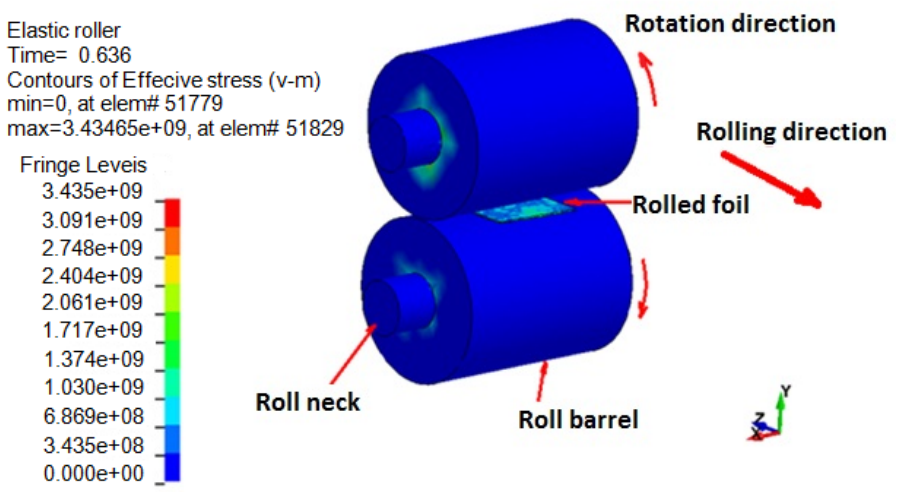

Fig. 3 Effective stress distribution 
Table 3 lists the property parameters of the roll and rolled material used in the simulation which are similar to the parameters in the real rolling experiment. In the process simulation, the roll rotates with a fixed angular speed. There is a predefined initial speed of the strip and once in the rolling bite zone, the strip is pulled forward due to the friction of the rolls. A surface-to-surface contact condition is applied between the rotating roll and the thin strip. The rolled strip is assumed to be isotropic elasto-plastic. Considering the elastic deformation, the work roll is assumed to be linear-elastic material and roll neck to be rigid material. The roll rotation is driven by roll neck. Fig. 3 shows the effective stress distribution in the simulation model for 2-Hi rolling process. Y direction is normal direction and $-\mathrm{Z}$ direction is the rolling direction. The simulation result is evaluated on the basis of rolling force distribution and surface characterization of the rolled strip.

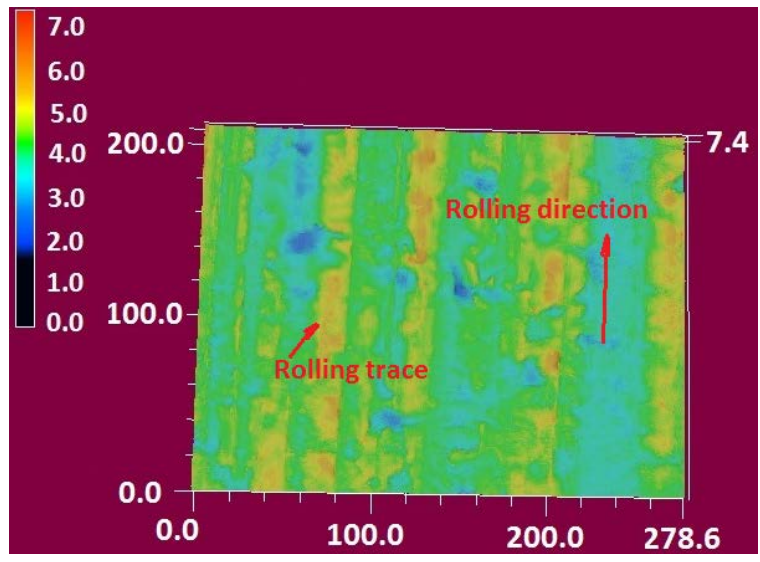

Fig. 4 Three dimensional measured heights of surface roughness, unit: $\mu \mathrm{m}$

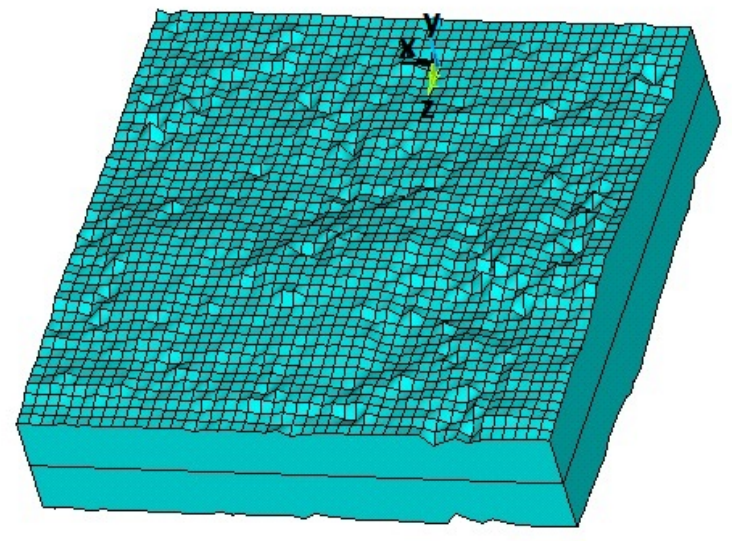

Fig. 5 Modelling surface roughness

Fig. 4 shows the three dimensional measured heights of surface roughness of the steel strip obtained from measurement system: 3D Laser Scanning Microscope, VK-X100 where the rolling direction and rolling trace have also been indicated. The surface roughness profile seems to be random but the characterization of height distribution is significant along rolling direction. In order to simulate the rolling process accurately, appropriate model for surface roughness across a large range of size scales is necessary. In this study the surface roughness has been modeled by ANSYS Parametric Design Language (APDL) based on the real measured value. Fig. 5 is the surface roughness modelling. Key points are firstly created at the base of the block and then bottom-up solid modelling approach is applied to create the block volume.

\section{RESULTS AND ANALYSIS}

\section{Flow stress of thin foil}

Scaled foil tensile test on standard commercial tensile testing machine is conducted for SUS304 stainless steel in different thicknesses. Fig. 6 shows the specimen size in tensile test. The nominal (engineering) stressstrain curves for different thicknesses of $50 \mu \mathrm{m}$ and $100 \mu \mathrm{m}$ along the rolling direction ( $0^{\circ}$ to rolling direction) are shown in Fig7. It can be seen that the yield strength in the thickness of $100 \mu \mathrm{m}$ is $5 \%$ higher than that in the thickness of $50 \mu \mathrm{m}$ in the as-received materials. The results indicate that flow stress of SUS304 stainless foil decreases with the decreasing foil thickness in tensile tests.

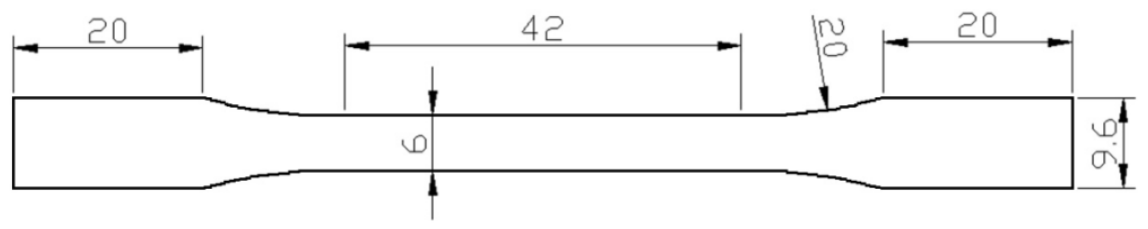

Fig. 6 Specimen in tensile test, unit: $\mathrm{mm}$

The experimental result that the stress decreases with scaling down can be explained by surface layer theory. The deformation behaviour of the surface material is different from the inside one as the free surface material is less constraint yielding a decreased flow stress $[2,9]$. The reduction of the flow stress with the thickness could have been resulted from the change of the volume ratio between the surface grains and the internal grains. This sort of ratio is smaller in marco-scale specimen where the surface material grains do not affect material 
properties significantly. However, the volume fraction of surface grain is increased tremendously when the specimen size is scaled down to micro-scale. With a reduction of the absolute strip thickness, the surface zone becomes relatively more important, leading to a larger decrease in stress than the prediction based on geometric similarity. Therefore the material deformation behaviour will be influenced by the feature size of the specimen thickness in micro forming.

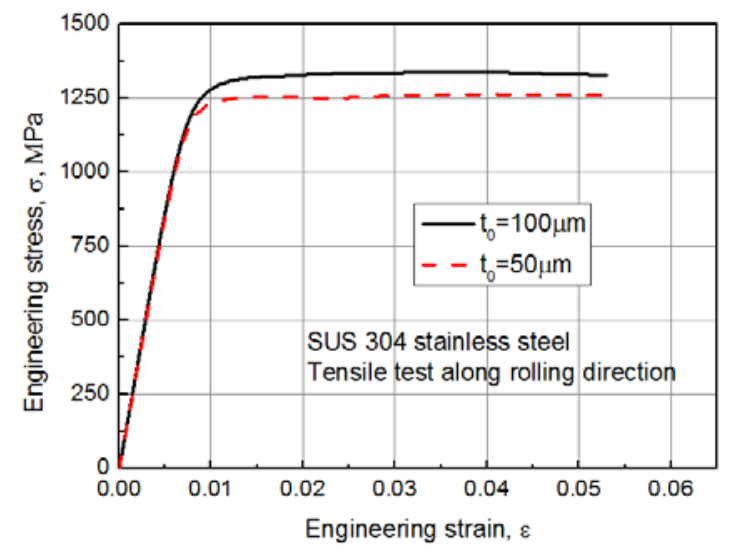

Fig. 7 Engineering Stress-Strain diagram for stainless steel

\section{Size effect on friction coefficient}

With increasing normal pressure, the real contact area increases due to more surface asperities flattened and the average friction coefficient increases as well. However, friction coefficient could decrease with an increase of close lubrication pool due to scaling down[6]. In order to investigate the size effect on friction coefficient and provide friction coefficient for simulation, the friction tester, as a simulator for micro forming, has been set up to measure the friction coefficient in dry sliding. The friction test is conducted through mounting new compression rig on standard commercial tensile testing machine [23]. In order to simulate the friction behaviour under the bulk plastic deformation of the strip, the contact pressure is varied and both surface and bulk deformations occur during sliding. The applied normal pressure is based on the contact pressure in rolling experiment.

The mean friction coefficient $\mu_{\text {mean }}$ can be calculated by Eq. 1 .

$$
\mu_{\text {mean }}=\frac{1}{L} \int_{0}^{L} \mu \cdot d l
$$

where, $\mathrm{L}$ is a sliding length and $\mu$ the friction coefficient for measured points during sliding in frictional test.

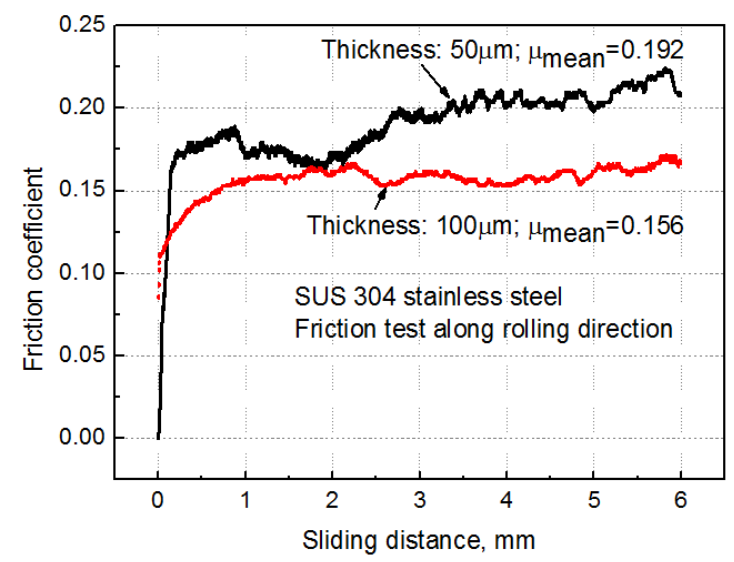

Fig. 8 Friction coefficient variation with sliding distance for different thicknesses

The results are shown in Fig. 8, demonstrating the relationship between the measured friction coefficients with sliding distances for different thickness specimens. It can be seen that the friction coefficient increases with 
decreasing foil thickness. The average friction coefficients are 0.192 and 0.156 for the thicknesses of $50 \mu \mathrm{m}$ and $100 \mu \mathrm{m}$, respectively, which will be applied in the simulation. A more interesting observation is that the friction coefficient increases with the sliding process and maximum values are 0.225 and 0.175 respectively for thickness of $100 \mu \mathrm{m}$ and $50 \mu \mathrm{m}$. This is due to the produced heat and the changed contact statue during dry sliding.

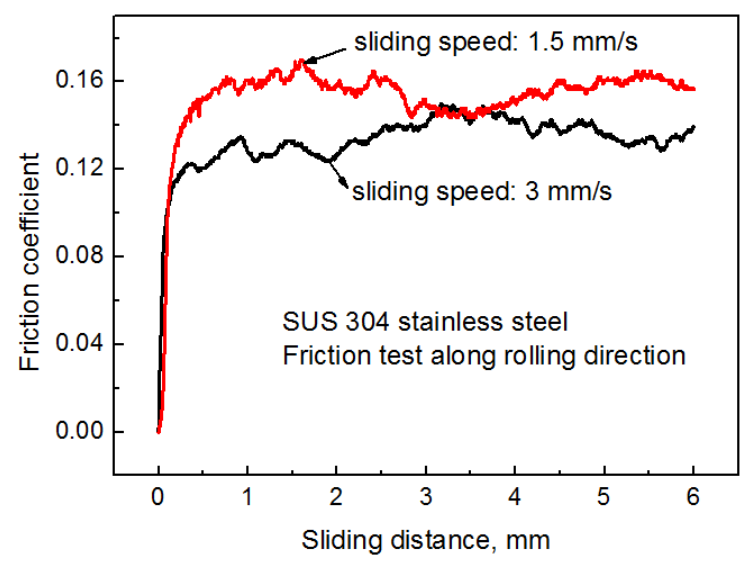

Fig. 9 Friction coefficient variations under two different sliding speeds, foil thickness: $100 \mu \mathrm{m}$

With similar experimental conditions except sliding speed, Fig.9 shows the average friction coefficient variations with different sliding speeds for the thickness of $100 \mu \mathrm{m}$. It can be seen that the average friction coefficient decreases with an increase of sliding speed. When the sliding speeds are $1.5 \mathrm{~mm} / \mathrm{min}$ and $3 \mathrm{~mm} / \mathrm{min}$ respectively, the average friction coefficients are 0.153 and 0.138 respectively. When the sliding speed is higher, the metal surface will soften due to the heat produced by the friction between the tool and the specimen. This softened layer acts as solid lubricant, which will cause friction coefficient to decrease with the sliding speed. Therefore the effect of speed on friction coefficient needs to be taken into account in the simulation. The friction coefficients under different speeds can be obtained from the friction test and its value can be applied in simulation through the linear interpolation based on the rolling speed accordingly.

\section{Rolling experiment and simulation}

A subroutine program in ANSYS has been set up. The detailed information of coordinates of nodes, faces, elements, and interface surfaces have been collected to evaluate the surface characterization in simulation.

The evaluated surface roughness $R_{a}$ can be expressed by:

$$
R_{a}=(1 / a) \int_{0}^{a}|Y(x)| d x
$$

where, $a$ is evaluation length value and $Y_{x}$ is the profile height function.

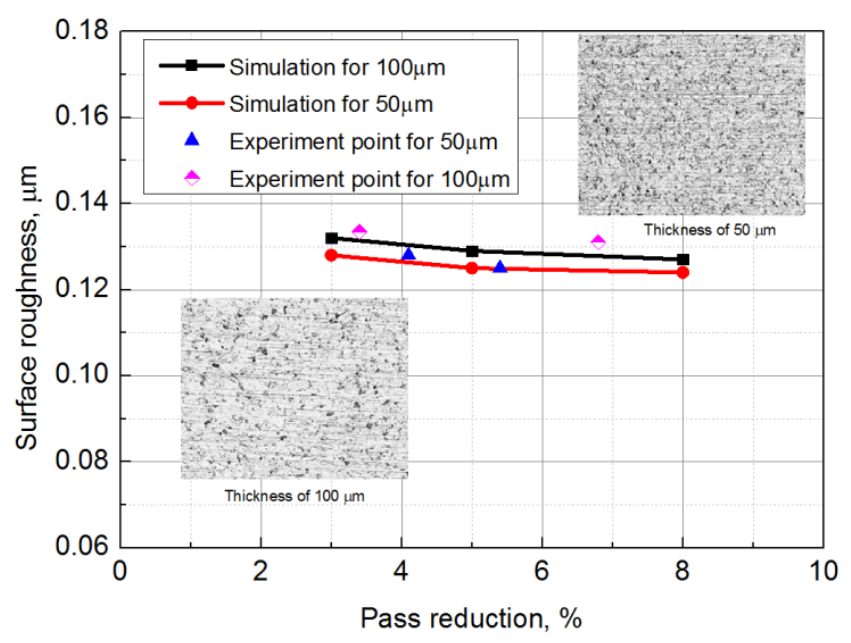

Fig. 10 Measured and predicted surface roughness 
Firstly, the bulk volume can be obtained through bottom up modelling by APDL Language as shown in Fig. 5. After rolling simulation, the coordinates of nodes on the topmost surface are collected to calculate the surface roughness based on Eq. 2.

The surface roughness in experiment versus simulation is shown in Fig10. The initial surface roughnesses are 0.136 and 0.132 for $100 \mu \mathrm{m}$ foil and $50 \mu \mathrm{m}$ foils, respectively. It can be seen that the surface roughness decreases with an increase of pass reduction due to the reprinting or interaction between the rolls and the rolled strip. The simulation results are in agreement with the experimental values, and this has testified the validation of rolling simulation modelling.

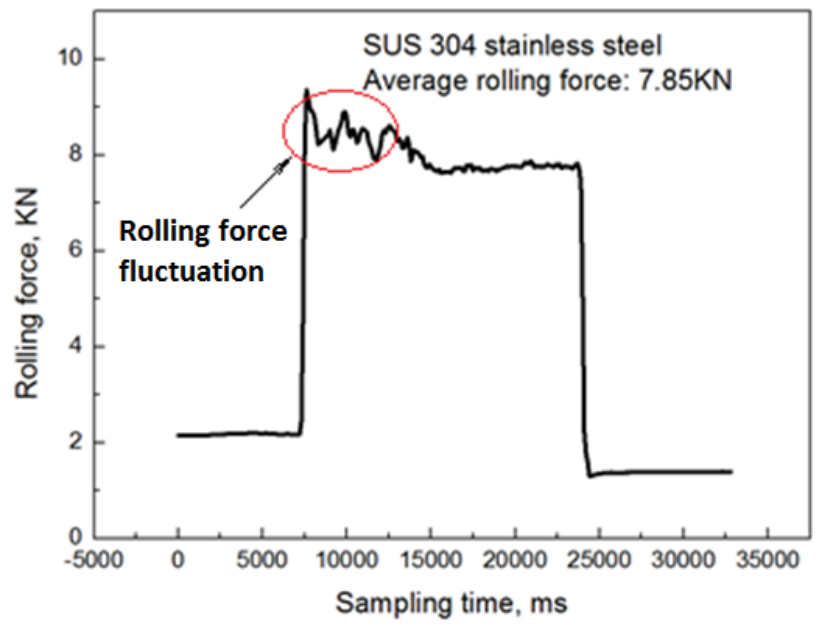

Fig. 11 Measured rolling force changes with sampling time in first pass, foil thickness: $100 \mu \mathrm{m}$

Fig. 11 shows the fluctuation of the measured rolling force with sampling time. Two pressure sensors are installed under both ends of the roll neck. The sensors are connected with the strain amplifier where so the rolling force can be recorded by the data logger as shown in Fig. 1. It can be seen that the rolling force variation is great when biting the rolling specimen in the rolling entrance as shown in the marked area in Fig. 11. After that, the rolling force reaches a steady state value with rolling process.

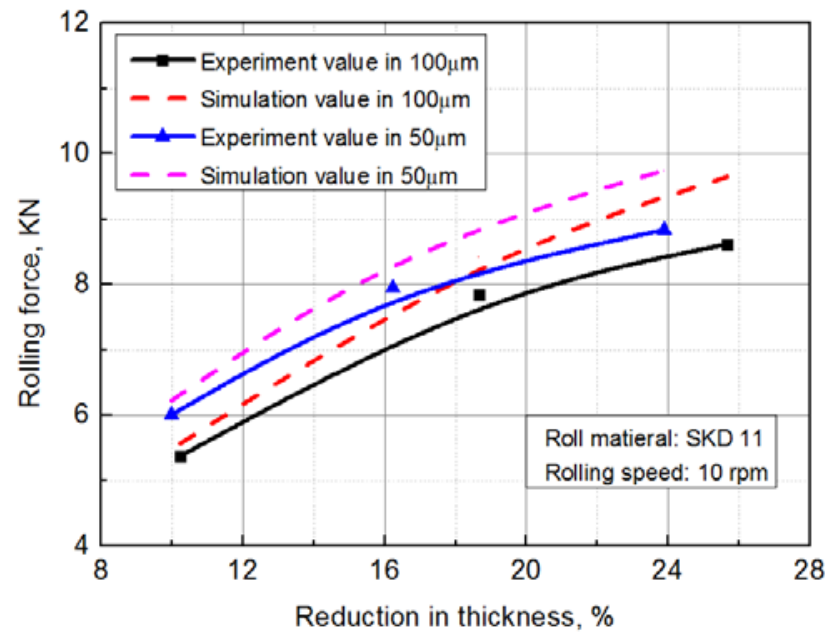

Fig. 12 Average rolling force versus rolling reduction

The rolling force comparison between the experiment and simulation is shown in Fig. 12. It can be seen that rolling force increases with increasing reduction in thickness. Through the comparison, the measured rolling forces are in agreement with the simulation results roughly and both graphs share the same upward sloping trend. The results of the experiment validate the simulation process. For the same reduction, the rolling force is higher in thinner foil than that in thicker foil.

In order to investigate the effect of elastic deformation of rolls on the foil deformation, two roll materials with different Young's Moduli are used in this simulation: SKD 11 and cemented carbide. Fig. 13 shows the effect of roll Young Modulus on the rolling force. It can be seen that more rolling force is required to obtain the 
same reduction in thickness for SKD 11 than that for cemented carbide. The higher the Young's modulus of the roll material, the lower is roll flattening. Therefore it is possible to obtain more reduction in thickness for the rolled strip using cemented carbide as roll material.

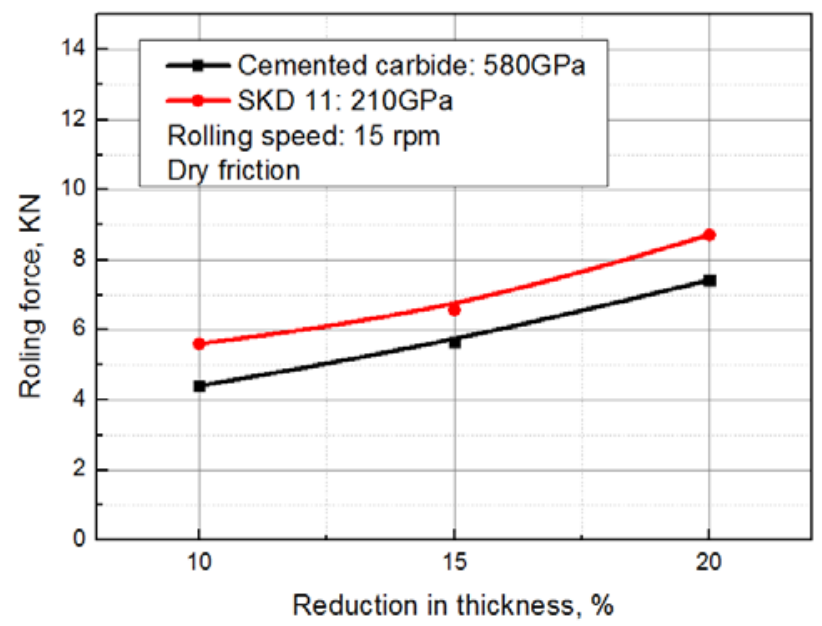

Fig. 13 Rolling force versus roll materials: SKD 11and Cemented carbide

\section{CONCLUSIONS}

A 2-Hi micro rolling mill has been successfully set up in foil rolling process for SUS 304 stainless steel and high quality ultra-thin foil has been obtained. Experiment and FE simulation have comprehensively investigated on this kind of foil in micro rolling. The results show that the friction coefficient increases with increasing miniaturization and with sliding distance as well. The flow stress in microforming process is decreased with the scaling down of specimen size. The size effects are demonstrated by the stress strain curve and the friction coefficient. Surface roughness decreases with increasing pass reduction. The fact that simulation results of surface roughness and rolling force are in good agreement with the experimental values testifies the validation of proposed modelling. The research results are able to provide a basis for understanding of deformation behaviour and friction phenomenon in micro rolling.

\section{ACKNOWLEDGEMENTS}

The authors would like to give thanks to Prof. Yoshino of Tokyo Institute of Technology and Prof. Koyama of Chiba University. The first author is grateful to the Japan Society for Promotion of Science (JSPS), Japan for awarding of JSPS post-doctoral fellowship (FY 2012-2014) to carry out research in Japan and the support from Australian Academy of Science (AAS). This research was supported by the Grant-in-Aid for JSPS Fellows relating to JSPS Post-doctoral Fellowship for Foreign Researchers (Grant No. 24.02770) from JSPS.

\section{REFERENCES}

1. Engel U, EcksteinR(2002) Microforming - from basic research to its realization.J Mater Process Technol125-126:35-44

2. Raulea LV, Goijaerts AM, Govaert LE, Baaijens FPT (2001)Size effects in the processing of thin metal sheets.J Mater Process Technol115:44-48

3. Yeh FH, Li CL, Lu YH (2008)Study of thickness and grain size effects on material behavior in microforming. J Mater Process Technol201:237-24

4. Parasiz SA, Kinsey BL, Mahayatsanun N, Cao J (2011) Effect of specimen size and grain size on deformation in microextrusion, J Manufact Process. 13: 153-159

5. Kals TA, Eckstein R (2000)Miniaturization in sheet metal working.J Mater Process Technol 103: 95-101

6. Peng LF, Lai XM, Lee HJ, Song JH, Ni J (2010) Friction behaviour modelling and analysis in micro/meso scale metal forming process. Mater Design 31: 1953-1961

7. Jeon J, Bramley AN (2007)A friction model for microforming.Int J Adv Manuf Technol33: 125-129 
8. Xie HB, Manabe K, Jiang ZY(2013) A novel approach to investigate surface roughness evolution in asymmetric rolling based on three dimensional real surface. Finite Elem Anal Des 74: 1-8

9. Wang GC, Zheng W, Wu T, JiangZ, Zhao GQ, Wei DB, Jiang ZY (2013) A multi-region model model for numerical simulation of micro bulk forming. J Mater Process Technol 212: 678-684

10. Le H, Sutcliffe M (2006) A multi-scale model for friction in cold rolling of aluminium alloy. Tribol Lett 22: 95-104

11. Le H, Sutcliffe M (2003) A friction model for cold strip rolling with two-wavelength surface roughness in the "mixed" lubrication regime. ASME J Tribol 125: 670-677

12. Lugt P, Wemekamp A, Napel W, Liempt P, Otten J (1993) Lubrication in cold rolling: elasto-plastohydrodynamic lubrication of smooth surfaces. Wear 166: 203-214

13. Xie HB, Jiang ZY, Du YB, Wei DB, Tieu AK (2009)Analysis of surface roughness of low carbon steel during cold rolling of thin strip. Adv Mat Res76-78: 544-547

14. Myshkin NK, Grigoriev AY, Chizhik SA, Choi KY, Petrokovets MI (2003) Surface roughness and texture analysis in microscale. Wear 254: 1001-1009

15. Sutcliffe MPF (1988) Surface asperity deformation in metal forming process. Int J Mech Sci 30: 847-868

16. Leu DK (2011) Modelling of surface roughness effect on dry contact friction in metal forming. Int J Manuf Technol 57: 575-584

17. Utsunomiya H, Sutcliffe MPF, Shercliff HR, Bate PS, Miller DB (2005) Influence of friction on roughening of the matt surface in aluminum pack rolling. IntJ Mach Tools Manufact 45: 803-809

18. Tateno J, Hiruta T, Katsura S, Honda A, Miyata T, Kamimaru A (2011) Experimental analysis of thickness reduction limits in ultra thin stainless steel foil rolling. ISIJ Int 51: 788-792

19. Yuen YWD, Dixon A, Nguyen DN (1996) The modelling of the mechanics of deformation in flat rolling. JMater Process Technol 60: 87-94

20. Zhang LC (1995) On the mechanism of cold rolling thin foil. Int J Mach Tools Manufact 35: $363-372$

21. Langlands TAM, McElwain DLS (2002) A modified Hertzian foil model: approximations based on perturbation methods. Int J Mech Sci 44: 1715-1730

22. Keife H, Shi JY, McElwain DLS, Langlands TAM (2002) Foil rolling: a new interpretation of experimental results. J Mater Process Technol 121: 50-59.

23.Shimizu T, Manabe K., Yang M(2010)Deformation behavior of ultra-thin metal foils in strip drawing friction test, Key Eng Mater 443: 110-115. 